\title{
Reduced E-cadherin expression correlates with disease progression in Paget's disease of the vulva but not Paget's disease of the breast
}

\author{
Patricia E Ellis ${ }^{1}$, Salvador Diaz Cano ${ }^{2}$, Mark Fear², David P Kelsell², Lucy Ghali², \\ Julie C Crow ${ }^{1}$, Christopher W Perrett ${ }^{1}$ and Allan B MacLean ${ }^{1}$
}

${ }^{1}$ Department of Obstetrics and Gynaecology, Royal Free and University College Medical School (Hampstead Campus), University College London, London, UK and ${ }^{2}$ Centre for Cutaneous Research, Institute of Cell and Molecular Sciences, Barts and The London Queen Mary's School of Medicine and Dentistry, London, UK

\begin{abstract}
The growth and metastasis of many cancers is due in part to loss of cell-cell adhesion. E-cadherin, plakoglobin and $\beta$-catenin are important in cell adhesion. Our aim was to examine the presence of these molecules in Paget's disease of the vulva and Paget's disease of the breast, and to correlate any differences in their expression with the presence of invasive disease or an underlying carcinoma. Sixty-three archival cases of Paget's disease of the vulva, including eight associated with invasive disease, and 23 archival cases of Paget's disease of breast, which included 10 cases with ductal carcinoma in situ alone, four cases with both ductal carcinoma in situ and invasive carcinoma, and five cases with underlying invasive carcinoma alone, were analysed immunohistochemically for expression of E-cadherin, plakoglobin and $\beta$-catenin proteins. The respective mRNAs were also detected by in situ hybridisation using digoxigenin-labelled cRNA probes. Seventy-six percent (41/54) of Paget's disease of vulva cases had $>50 \%$ of Paget cells expressing the Ecadherin protein, compared with $28 \%(2 / 7)$ of Paget's disease vulva with invasive disease. This result was significant, with a $P$-value of 0.039 . Twenty-five percent (14/55) of the intraepidermal Paget's disease of the vulva cases had $>50 \%$ of Paget cells expressing the plakoglobin protein, compared with $12 \%(1 / 8)$ of cases of Paget's disease of vulva with invasive disease, and for $\beta$-catenin, $9 \%(5 / 55)$ of the non-invasive Paget's disease of the vulva had $>50 \%$ of Paget cells expressing $\beta$-catenin, compared with $12 \%(1 / 8)$ of Paget's disease of the vulva cases with invasive disease. Sixty-five percent (15/23) of the Paget's disease of the breast had $>50 \%$ of Paget cells expressing E-cadherin, and for plakoglobin and $\beta$-catenin it was $17 \%(4 / 23)$ and $28 \%(6 / 21)$, respectively. The results were not significant. The results suggest that reduced expression of E-cadherin may have a role to play in the pathogenesis of invasive Paget's disease of the vulva. Abnormal plakoglobin expression may be involved in the formation of some cases of Paget's of the vulva and the breast.
\end{abstract}

Modern Pathology (2008) 21, 1192-1199; doi:10.1038/modpathol.2008.50; published online 9 May 2008

Keywords: E-cadherin; Paget's disease; vulva

Paget's disease of the vulva was described 100 years ago. ${ }^{1}$ It is rare and there still is a limited understanding about its association with cancer. Most cases of Paget's disease of the vulva are adenocarcinoma in situ disease; however, in some cases there is an associated invasive adenocarcinoma present. Previous studies ${ }^{2,3}$ have suggested that the frequency of occurrence of an associated underlying carcinoma is of the order of $10-30 \%$. Some theories

Correspondence: Dr PE Ellis, MBBS, MD, c/o Professor Allan MacLean, Department of Obstetrics and Gynaecology, Royal Free and University College Medical School (Hampstead Campus), University College London, Rowland Hill Street, London NW3 2PF,UK. E-mail: peellis@hotmail.com

Received 01 October 2007; revised and accepted 01 February 2008; published online 9 May 2008 suggest that intraepidermal adenocarcinoma cells have metastasised to the overlying surface from the underlying carcinoma, whereas others have suggested that Paget cells migrate downwards to develop invasive disease. ${ }^{4}$ In contrast to Paget's disease of the vulva, the general consensus for Paget's disease of the breast, which was originally described by Sir James Paget in $1874,{ }^{5}$ is that almost all cases are associated with a ductal carcinoma in situ (DCIS) or an invasive ductal carcinoma. ${ }^{6}$

Cells within the epidermis are held together by a number of adhesion complexes and their associated proteins. The growth of many cancer cells has been linked to the loss of negative regulation of cell proliferation conferred by cell-cell adhesion. The reduced expression or lack of cell adhesion molecules has therefore been implicated in the invasion and 
metastatic process. ${ }^{7}$ Loss or decreased cell adhesiveness has been demonstrated in cancers and thought to represent a greater risk of tumour dissemination. ${ }^{8}$

E-cadherin is a member of a multifunctional family of calcium-dependent, transmembrane glycoproteins, which promote and maintain cell adhesion. ${ }^{9}$ In vitro experiments have demonstrated E-cadherin to have invasion-suppressing properties. ${ }^{10,11}$ Downregulation of E-cadherin expression has been documented in breast ${ }^{12}$ and oesophageal carcinomas, ${ }^{7}$ squamous cell carcinomas of the skin ${ }^{13}$ and bladder carcinomas. ${ }^{14}$ Plakoglobin and $\beta$-catenin are closely related proteins that have a key role in cell adhesion (adherens junctions), ${ }^{15}$ activation of transcriptional factors, for example, T-cell factor (Tcf) ${ }^{16}$ and in the Wnt wingless-signalling pathways, ${ }^{17}$ an important pathway in the development of the cell and cancer.

The objective of this study was to determine whether expression of E-cadherin, plakoglobin and $\beta$-catenin correlated with disease progression in Paget's disease of the vulva and Paget's disease of the breast, in order to investigate the role of the proteins as potential diagnostic markers. This study complements our other work investigating the role of the cell cycle and angiogenesis in Paget's disease of the vulva and Paget's disease of the breast. ${ }^{18,19}$

\section{Materials and methods}

\section{Tissue Specimens}

Ethical approval has been granted by the Royal Free Hospital NHS Trust.

Sixty-three cases of Paget's disease of the vulva, including eight associated with invasive disease, and 23 cases of Paget's disease of the breast, which included 10 cases with DCIS alone, four cases with both DCIS and invasive carcinoma, five with an underlying invasive carcinoma, and four with Paget's disease of the breast alone, were analysed for expression of E-cadherin, plakoglobin and $\beta$-catenin. These cases were retrieved from the Histopathology Department at the Royal Free Hampstead NHS Trust, and from collaborators as listed in the acknowledgement section. The cases were diagnosed and treated between 1984 and 2000.
The archival cases had all been formalin-fixed and paraffin wax-embedded. Drs Diaz-Cano (SDC) and Julie C Crow (JCC; collaborating Histopathologists) reviewed all haematoxylin and eosin-stained slides of the cases to confirm diagnosis of Paget's disease.

\section{Immunohistochemistry}

The streptavidin-biotin-peroxidase detection system was employed for immunohistochemistry.

Paraffin wax-embedded sections of Paget's tissue, $5-\mu \mathrm{m}$ thick, were cut and mounted on aminopropyltriethoxysilane-coated glass slides. The sections were deparaffinised in xylene $(2 \times 5 \mathrm{~min})$ and rehydrated in graded solutions of ethanol (100, 90 and $70 \%, 3$ min each). To block endogenous peroxidase, sections were immersed in 3\% hydrogen peroxide in methanol for $10 \mathrm{~min}$. The sections were then left in running water $(2 \mathrm{~min})$. Conditions for antigen retrieval, incubation times and the primary antibodies used are described in Table 1. Sections were incubated with the secondary antibody, biotinylated rabbit anti-mouse IgG (1:50 dilution in phosphate buffered-saline, PBS; Dako) for $30 \mathrm{~min}$ and washed in PBS $(3 \times 5 \mathrm{~min})$. Addition of streptavidin-biotinhorseradish peroxidase complex (Dako) to the sections (1:500 dilution in Tris-buffered saline) for $30 \mathrm{~min}$ was followed by a further wash in PBS (3 min). Antibody binding was visualised with a solution containing the chromogen 3,3'-diaminobenzidine (Sigma-Aldrich, Poole, UK). The sections were counterstained with Mayer's haematoxylin (Merck, Lutterworth, UK). Finally, slides were rehydrated in graded ethanol rinses, cleared in xylene and mounted in DPX.

Normal vulval skin was used as positive control for cases of Paget's disease of the vulva, and normal breast skin was for cases of Paget's disease of the breast. Apocrine and eccrine glands were used as internal controls. For negative controls, the primary antibodies were replaced by PBS. Sections were stained on two separate occasions and scored separately by two individuals (SDC, PEE) to ensure reproducibility. There was $<5 \%$ variation between sections and observers.

Table 1 Antibodies used, antigen retrieval and incubation times used for immunhistochemistry. Forward and reverse primer sequences used for PCR

\begin{tabular}{|c|c|c|c|c|c|c|}
\hline Antigen & Source & Clone & Working dilution $^{\mathrm{a}}$ & Antigen retrieval & Incubation time & Primer \\
\hline E-cadherin & Zymed & 36 & $1: 250$ & $\begin{array}{l}\text { Microwave } \\
\text { Pressure cooking }\end{array}$ & $11 / 2 \mathrm{~h}$ & $\begin{array}{l}\text { TTAGGTTAGAGGGTTATCGCGT } \\
\text { TAACTAAAAATTCACCTACCGAC }\end{array}$ \\
\hline Plakoglobin & Zymed & 15 & $1: 100$ & $\begin{array}{l}\text { Microwave } \\
\text { Pressure cooking }\end{array}$ & $11 / 2 \mathrm{~h}$ & $\begin{array}{l}\text { GCCTGCCTTCTTCTTGTGTC } \\
\text { CTGAAGCTTTAGTGGCCAGG }\end{array}$ \\
\hline$\beta$-Catenin & Zymed & 14 & $1: 50$ & None & $11 / 2 \mathrm{~h}$ & $\begin{array}{l}\text { GGAGGTCTCCTTGGGACTC } \\
\text { ACTAGTCGTGGAATGGCACC }\end{array}$ \\
\hline
\end{tabular}

${ }^{\mathrm{a}}$ Diluted in PBS. 
The location of the pattern of staining of the protein was recorded as one of the following: membranous, diffuse cytoplasmic, paranuclear and nuclear. To score, initially four quarters as a percentage of Paget cells expressing each protein were used. However, since the numbers were small in each group, $50 \%$ positivity was used as threshold. The intensity of staining was also recorded as either nil, mild or strong.

\section{In Situ Hybridisation}

Paraffin-wax-embedded sections (5- $\mu$ m thick) were cut on Superfrost slides (Merk). Sections were deparaffinised, microwaved in pre-warmed $10 \%$ citrate buffer $(10 \mathrm{~min})$ and pre-hybridised at $42^{\circ} \mathrm{C}$ for $4 \mathrm{~h}$. Following this, sections were hybridised with $40 \mathrm{ng} / \mu \mathrm{l}$ of digoxigenin-labelled cRNA probe in pre-hybridisation buffer containing $20 \%$ dextran sulphate for overnight at $42^{\circ} \mathrm{C}$, using a Hybaid Omnislide machine. Following stringency washes to $0.1 \times$ SCC $/ 50 \%$ formamide, sections were stained with anti-digoxigenin-alkaline phosphatase Fab fragments. After washing, sections were developed with nitroblue tetrazolium chloride/bromo-chloroidoly-phosophate (Sigma) chromogen solutions. Stained sections were scored for intensity of the mRNA signal at the intracellular junctions. Nuclear and cytoplasmic staining were recorded separately. Sections were stained on two separate occasions and the results analysed by two independent observers (PEE and Lucy Ghali (LG)). There was $<5 \%$ variation between sections and observers. The surrounding apocrine glands and epidermal cells were used as positive controls. The sense (mRNA) probe was used as the negative control. Primer sequences for E-cadherin, plakoglobin and $\beta$-catenin are described in Table 1.

\section{Statistical Analysis}

Statistical analysis was performed by $\chi^{2}$ and Fisher's exact tests, as appropriate. A $P$-value of $<0.05$ was considered significant.

\section{Results}

\section{Evaluation of E-cadherin, Plakoglobin and $\beta$-Catenin in Paget's Disease of the Vulva Without Invasive Disease}

Forty-one of the 54 (76\%) cases of Paget's disease of the vulva without invasive disease had $>50 \%$ of Paget cells expressing E-cadherin (Figure 1). The staining pattern was membranous and the intensity of staining was mostly strong.

Six cases were suitable for scoring E-cadherin mRNA. Decreased mRNA signal in the Paget cells (Figure 2) was noted in all cases, as compared with

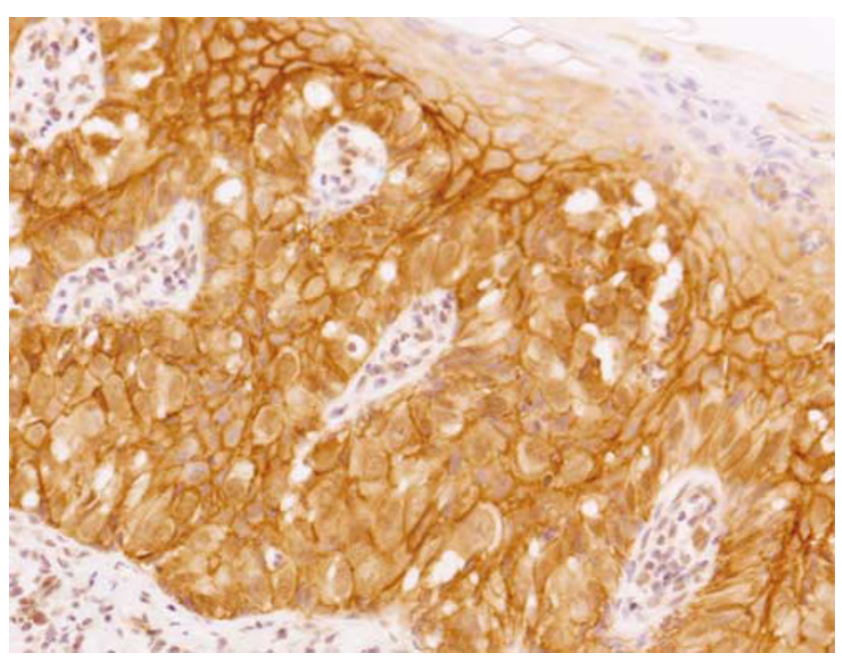

Figure 1 E-cadherin protein expression in non-invasive Paget's disease of the vulva $(\times 200)$ with a score of $<50 \%$.

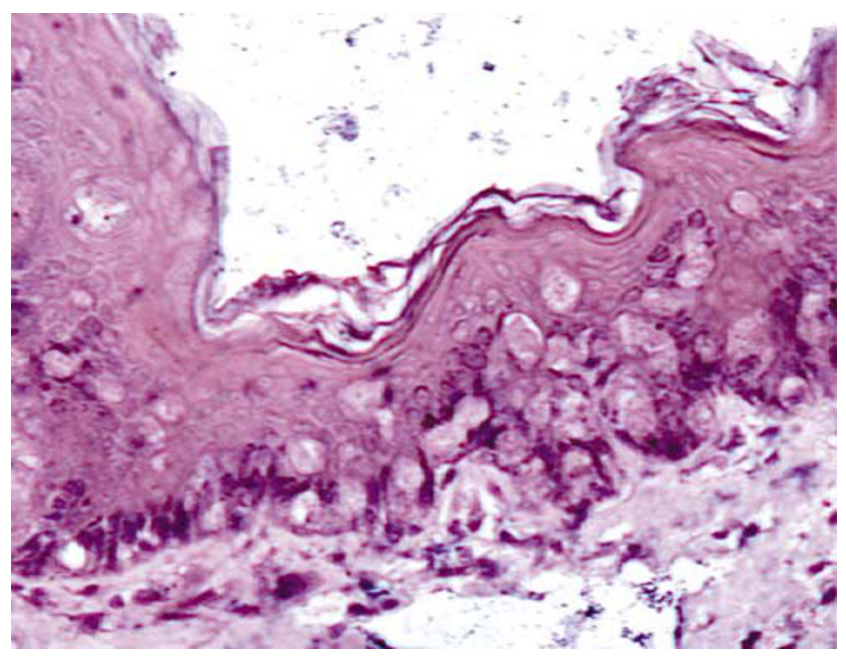

Figure 2 E-cadherin mRNA signal in Paget cells in non-invasive Paget's disease of the vulva $(\times 200)$.

the surrounding apocrine glands and epidermal cells.

Fourteen of $55(25 \%)$ cases had $>50 \%$ of Paget cells expressing plakoglobin compared with $74 \%$ with a score of $<50 \%$ (Figure 3 ). In most cases the staining pattern was membranous and the staining intensity mild. Ten Paget's disease of the vulva cases were analysed for plakoglobin mRNA, but only eight were suitable for scoring. All cases had decreased mRNA signal in the Paget cells, compared with in the apocrine and epidermal cells.

Only 5 of $55(9 \%)$ cases had $>50 \%$ of Paget cells expressing the $\beta$-catenin protein, compared with 50 of $55(91 \%)$ of cases with $<50 \%$ (Figure 4). Again, staining was membranous and intensity was mild. Fifteen cases were analysed for $\beta$-catenin mRNA, but only nine were suitable for scoring. Eight cases revealed decreased mRNA signal in the Paget cells, compared with the surrounding apocrine glands and epidermal cells. 


\section{Paget's Disease of the Vulva with Invasive Disease}

Two of seven (28\%) cases had $>50 \%$ of Paget cells expressing E-cadherin. This result was significant, $P$-value $=0.039$, when compared with $41 / 54(76 \%)$ of Paget's disease of the vulva cases without invasive disease.

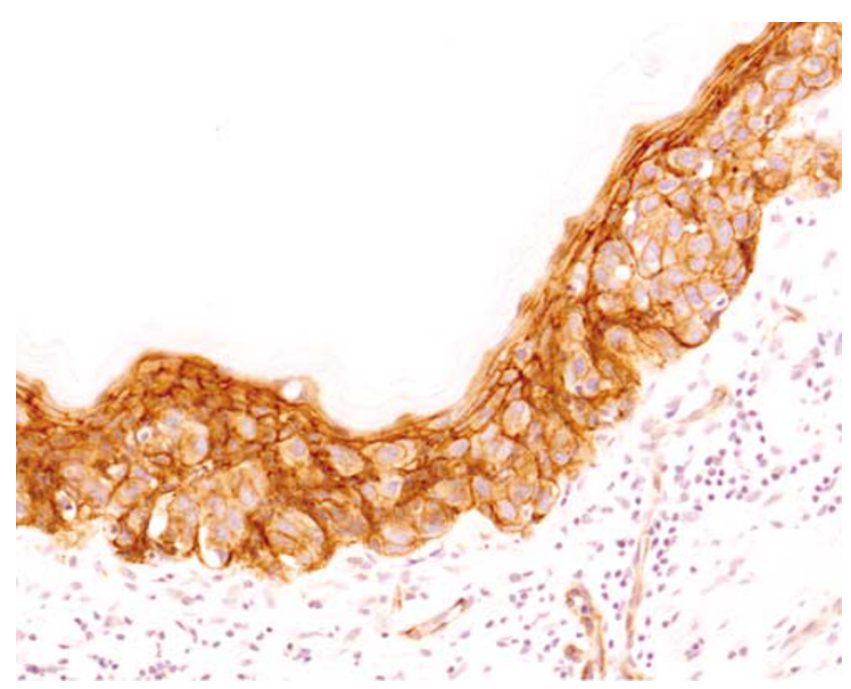

Figure 3 Plakoglobin protein expression in non-invasive Paget's disease of the vulva, with a score of $<50 \%$.

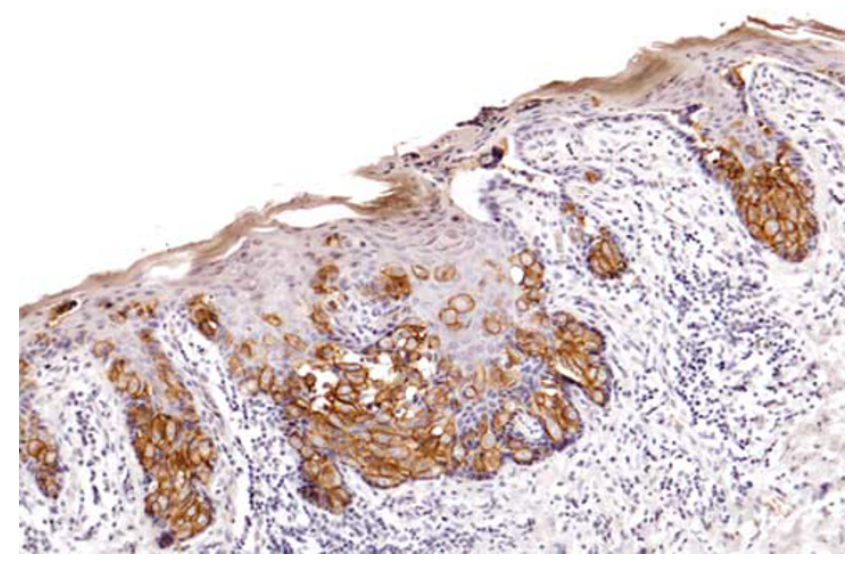

Figure $4 \beta$-Catenin protein expression in non-invasive Paget's disease of the vulva $(\times 200)$ with a score of $<50 \%$.
One of eight ( $12 \%$ ) cases had $>50 \%$ of Paget cells expressing the plakoglobin and $\beta$-catenin protein, respectively. The results were not significant when comparing with Paget's disease of the vulva cases without invasive disease. The staining pattern was found to be membranous, cytoplasmic and nuclear, and staining intensity was mild. One case of invasive Paget's disease of the vulva was suitable for scoring E-cadherin and plakoglobin mRNA. Decreased mRNA signal in the Paget cells was noted in both cases as compared with the surrounding apocrine glands and epidermal cells. The results are presented in Table 2.

\section{Evaluation of E-cadherin, Plakoglobin and $\beta$-Catenin Expression in Paget's Disease of the Breast}

In Paget's disease of the breast with DCIS alone (10 cases), 5 cases (50\%) had $>50 \%$ of Paget cells expressing E-cadherin. Only one case (10\%) had $>50 \%$ of Paget cells expressing plakoglobin, and 2 cases $(20 \%)$ expressed $\beta$-catenin. Of the four cases of Paget's disease of the breast with DCIS and invasive disease, all (100\%) had $>50 \%$ of Paget cells expressing E-cadherin, and $2(50 \%)$ had $>50 \%$ of Paget cells expressing plakoglobin and $\beta$-catenin.

There were five cases of Paget's disease of the breast with invasive disease, of which four $(80 \%)$ had $>50 \%$ of Paget cells expressing E-cadherin. One case $(20 \%)$ had $>50 \%$ of Paget cells expressing plakoglobin and two cases $(40 \%)$ had $>50 \%$ of Paget cells expressing $\beta$-catenin. Of the four cases of Paget's disease of the breast alone, two (50\%) had $>50 \%$ of Paget cells expressing E-cadherin (Figure 5). Plakoglobin and $\beta$-catenin were not expressed in $>50 \%$ of Paget cells (Figure 6). There was no significant difference between the subsets of Paget's disease of the breast expressing E-cadherin, plakoglobin and $\beta$-catenin proteins. Table 2 shows the subsets' combined expression of E-cadherin, plakoglobin and $\beta$-catenin proteins. Nine of the 14 Paget's disease of breast cases, which included 4 with associated DCIS, 4 with invasive carcinoma and one case of Paget's disease of the breast only, analysed were suitable for E-cadherin mRNA scoring. In all cases, the mRNA signal was found to be reduced in the Paget cells as compared with the surrounding apocrine glands and epidermal cells.

Table 2 E-cadherin, plakoglobin and $\beta$-catenin expression in Paget's disease of the vulva and Paget's disease of the breast

\begin{tabular}{|c|c|c|c|c|}
\hline Protein expression & $\begin{array}{l}\text { Paget's disease of the vulva } \\
\text { with invasive disease } \\
\text { (threshold of positivity) }\end{array}$ & $\begin{array}{l}\text { Paget's disease of the vulva } \\
\text { without invasive disease } \\
\text { (threshold of positivity) }\end{array}$ & $\mathrm{P}$-value & $\begin{array}{l}\text { Paget's disease of the } \\
\text { breast (threshold of } \\
\text { positivity) }\end{array}$ \\
\hline E-cadherin & $2 / 7(>50 \%)$ & $41 / 54(>50 \%)$ & $\begin{array}{c}P=0.039 \\
\text { significant }\end{array}$ & $15 / 23(>50 \%)$ \\
\hline Plakoglobin & $1 / 8(>50 \%)$ & $14 / 55(>50 \%)$ & $P=0.77$ & $4 / 23(>50 \%)$ \\
\hline$\beta$-Catenin & $1 / 8(>50 \%)$ & $5 / 55(>50 \%)$ & $P=0.96$ & $6 / 21(>50 \%)$ \\
\hline
\end{tabular}

$P$-value for Paget's disease of the vulva with invasive disease compared with Paget's disease without invasive disease. 


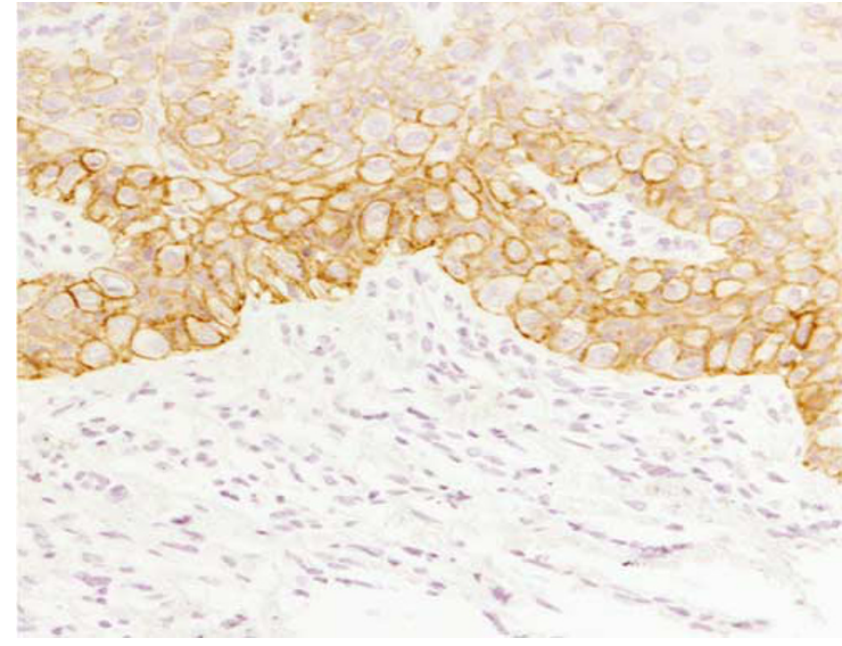

Figure 5 E-cadherin protein expression in Paget's disease of the breast alone $(\times 200)$ with a score of $>50 \%$.

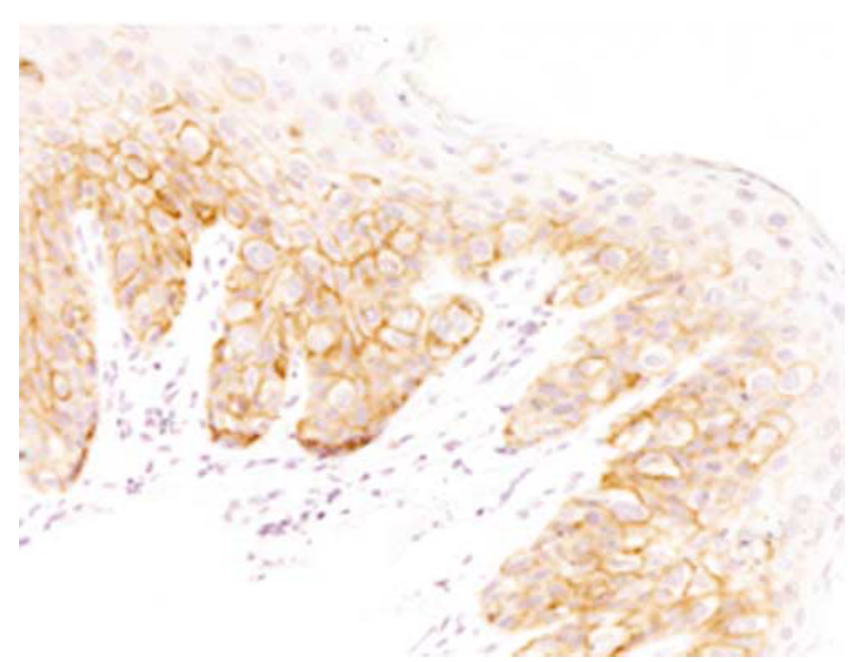

Figure $6 \beta$-Catenin protein expression in Paget's disease of the breast alone $(\times 200)$ with a score of $<50 \%$.

Eight of 11 cases of Paget's disease of the breast, which included 5 with associated DCIS, 4 with invasive carcinoma and 2 with Paget's disease of the breast only, were suitable for scoring mRNA plakoglobin. The mRNA signal was noted to be decreased or absent in the Paget cells, as compared with the surrounding apocrine glands and epidermal cells.

Thirteen cases of Paget's disease of the breast were analysed for $\beta$-catenin mRNA, which included 6 with associated DCIS, 4 with invasive carcinoma and 2 with Paget's disease of breast only. In the 12 cases that were suitable for scoring, mRNA signal was noted to be decreased in 10 cases as compared with the surrounding apocrine glands and epidermal cells (Figure 7). The signal was found to be similar in intensity in both the antisense and sense slides in two cases.

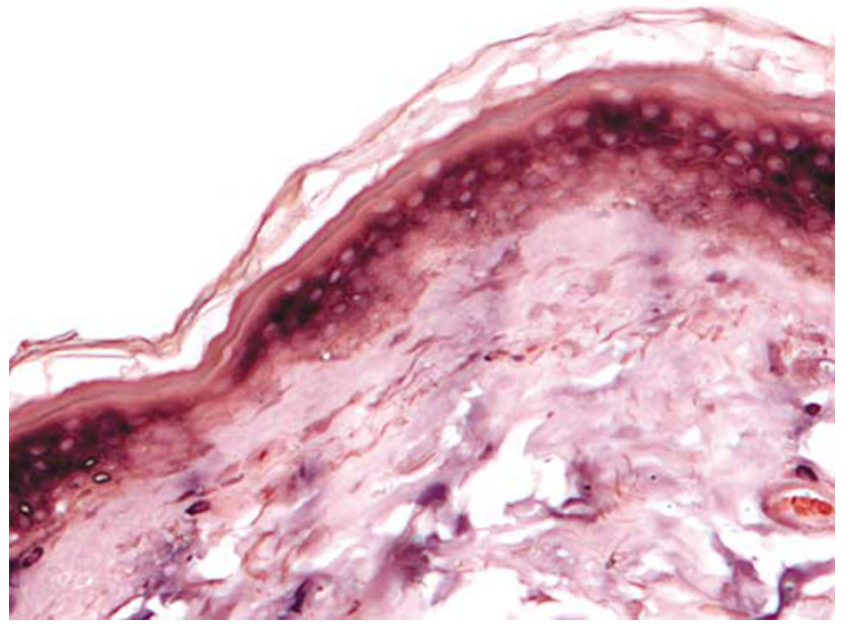

Figure $7 \beta$-Catenin mRNA signal in Paget's disease of the breast alone $(\times 100)$.

\section{Discussion}

\section{E-cadherin Expression in Paget's Disease of the Vulva}

This is the largest study of E-cadherin, plakoglobin and $\beta$-catenin expression in Paget's disease of the vulva and Paget's disease of the breast of which we are aware. Since loss of expression of E-cadherin has been suggested as one of the mechanisms contributing to development of invasion and metastasis of cancer cells, its expression has been investigated in several cancers with a view to correlating lack of expression with invasive disease. Only two smaller studies have examined this role in Paget's disease of the vulva. The Shirahama et al study ${ }^{20}$ found that E-cadherin was not expressed in their three cases of Paget's disease of the vulva, and Tada and coworkers ${ }^{21}$ showed decreased expression of E-cadherin in their invasive Paget's disease of the vulva (four cases) compared with the in situ cases (four cases).

In the current study we found similar results. E-cadherin expression was significantly reduced $(P=0.039)$ in the intraepidermal compartment of the Paget's disease of the vulva cases with invasive disease when compared with the intraepidermal compartment of Paget's disease of the vulva cases without invasive disease. Loss of E-cadherin expression is likely to lead to reduced cell adhesiveness and therefore detachment of Paget cells from the intraepidermal lesion, the result being invasive disease. There appeared to be no significant difference in the cellular localisation of the proteins between non-invasive and invasive Paget's disease of the vulva.

There was a decrease in mRNA signal intensity when compared with the surrounding apocrine glands and epidermal cells, in both non-invasive Paget's disease of the vulva, and in those cases associated with invasive disease, suggesting decreased transcriptional regulation of the protein 
rather than factors affecting its stability and degradation.

\section{Plakoglobin Expression in Paget's Disease of the Vulva}

The reduced expression of cell adhesion molecules has been implicated in promoting invasion and metastasis. ${ }^{22,23}$ There is a paucity of information regarding expression of plakoglobin, E-cadherin and $\beta$-catenin in Paget's disease of the vulva and, as such, the role of these molecules has not been clearly established in Paget's disease of the vulva. ${ }^{20,21,24}$ To our knowledge, only one study has examined the expression of plakoglobin in Paget's disease of the vulva. Tada et $a l^{24}$ examined the expression of desmoglein I and plakoglobin in skin carcinomas, which included 11 cases of extramammary Paget's disease; only one case was from a female of which the location was documented as the pudendum. This case was negative for plakoglobin. In the current study, fewer Paget cells expressed plakoglobin in the intraepidermal compartment of the Paget cases with invasive disease when compared with the intraepidermal compartment of Paget's disease cases without invasive disease, although this did not reach statistical significance. Plakoglobin mRNA signal was also decreased compared with the surrounding apocrine glands. These findings may suggest a possible dysfunction in the regulation of plakoglobin in Paget's disease of the vulva with invasive disease, as compared with those cases without invasion. Nuclear and diffuse cytoplasmic staining of the plakoglobin protein was noted in 13 of the cases, with only one case being associated with invasive disease.

\section{$\beta$-Catenin Expression in Paget's Disease of the Vulva}

The transcriptional activity of $\beta$-catenin and its degradation are regulated by the Wnt pathway. In normal epithelial cells, $\beta$-catenin is localised at the cell membrane. The unbound $\beta$-catenin is degraded by the ubiquitin-proteasome system, which involves the GSK-3 $\beta$. Stabilisation of cytoplasmic $\beta$-catenin by aberrant activation of Wnt signalling leads to its accumulation, complex with lymphoid enhancer factor/Tcf (LEF/Tcf) transcription factors and transactivation of LEF/Tcf target genes. Activation of these genes can lead to cell proliferation or inhibition of apoptosis. Nuclear accumulation of $\beta$-catenin can be the result of gene mutations. ${ }^{25}$ In colon cancers, disruption of the Wnt-signalling pathway by mutations of either the adenomatous polyposis coli or the $\beta$-catenin gene plays a crucial part in the early stage of tumorigenesis. ${ }^{26}$ In the current study, diffuse cytoplasmic and paranuclear staining of the $\beta$-catenin protein was found in 11 and four cases of Paget's disease of the vulva, respectively. Three of these cases were of Paget's disease of the vulva with invasion. These results may suggest involvement of aberrant activation of the Wnt-signalling pathway in some cases of Paget's disease of the vulva.

\section{E-cadherin Expression in Paget's Disease of the Breast}

The role of E-cadherin in breast cancers is debatable. Reduced expression of E-cadherin has been reported to be associated with poor outcome ${ }^{27}$ whereas other investigators have demonstrated no independent prognostic value for E-cadherin in breast carcinomas. ${ }^{28,29}$ To our knowledge, only one study ${ }^{21}$ has examined the expression of E-cadherin in Paget's disease of the breast, and both cases were negative for the protein. In contrast, in our larger study, 65\% of the Paget's disease of the breast cases in our study had $>50 \%$ of Paget cells expressing E-cadherin. It is therefore unlikely that reduced E-cadherinmediated cell-cell adhesion is an important factor in the pathogenesis of Paget's disease of the breast.

\section{Plakoglobin Expression in Paget's Disease of the Breast}

Plakoglobin has not been examined in Paget's disease of the breast, although it has been examined in primary breast carcinomas. ${ }^{30-33}$ Loss of heterozygosity and reduced expression of plakoglobin associated with disease progression have been demonstrated in breast cancer. In the current study, only $17 \%$ of the cases of Paget disease of the breast had $>50 \%$ of Paget cells expressing plakoglobin. This implicates a possible role for plakoglobin in the formation of Paget's disease of the breast. There was good correlation between plakoglobin mRNA and protein expression.

\section{$\beta$-Catenin Expression in Paget's Disease of the Breast}

Few studies have sought to examine the role of $\beta$-catenin in breast carcinomas, ${ }^{30,31}$ and none have examined $\beta$-catenin in Paget's disease of the breast. Forty-eight percent of our cases of Paget's disease of the breast had nuclear and paranuclear staining of $\beta$-catenin protein. The extramembranous accumulation could be due to mutation in the $\beta$-catenin gene or its lack of degradation by the APC/GSK $3 \beta$ / proteasome system. Except in one case, there was good correlation between mRNA signal and protein expression.

The adhesive function of cadherins is dependent on their interaction with catenins. Some reports have revealed reduced expression of both cadherins and catenins in certain tumours, for example, oral squamous cell carcinoma. $^{34}$ In the current study, there appeared to be no correlation between reduced expression of E-cadherin and $\beta$-catenin.

In summary, reduced expression of E-cadherin may a have a role in the pathogenesis of Paget's disease of the vulva with invasive disease, unlike in 
Paget's disease of the breast, where in the majority of cases, normal expression of the protein was demonstrated. Abnormal plakoglobin expression may be involved in some cases of Paget's disease of the vulva and Paget's disease of the breast. These results suggest that there may be different mechanisms underlying the aetiology of these two diseases, and loss of cell-cell adhesion may be an important factor in their development.

\section{Acknowledgement}

We thank the following for their assistance in obtaining cases of Paget's disease of the vulva and Paget's disease of the breast: Dr C Andrews (The General Infirmary, Leeds), Dr S Andrews (Hope Hospital, Manchester), Dr L Brown (Leicester Royal Infirmary, Leicester), Dr E Courtauld (Farrer-Brown Laboratory, London), Dr P Cross (Queen Elizabeth Hospital, Gateshead), Dr A Desai (Whittington Hospital, London), Dr R Dino (Queen Charlotte's and Chelsea Hospital, London), Dr A Flanagan (St Mary's Hospital, London), Dr J Johnson (Nottingham City Hospital, Nottingham), Professor $\mathrm{T}$ Krauz (Hammersmith Hospital, London), Dr S Lakhani (University College London), Professor D Lowe (St Bartholomew's Hospital, London), Dr P Millard (The John Radcliffe Hospital, Oxford), Dr N Nasseri (The Royal Marsden Hospital, London), Dr J Smith (The Northern General Hospital, Sheffield), Dr P Trott (The London Clinic, London), Professor M Wells (The Royal Hallamshire Hospital, Sheffield), Dr G Wilson (Manchester Royal Infirmary, Manchester), Dr M Young (St George's Hospital, London). Partial support for P Ellis came from the South Essex Medical Education and Research Trust, UK.

\section{Duality of interest}

There was no duality of interest in this study.

\section{References}

1 Dubreuilh W. Paget's disease of the vulva. $\mathrm{Br}$ J Dermatol 1901;13:407-413.

2 Chanda JJ. Extramammary Paget's disease: prognosis and relationship to internal malignancy. J. Am Acad Dermatol 1985;113:1009-10013.

3 Bohem F, Morris JMCL. Paget's disease and apocrine gland carcinoma. Obstet Gynaecol 1971;38:185-192.

4 Fox H, Wells M. Recent advances in the pathology of the vulva. Histopathology 2003;42:209-216.

5 Paget J. On the disease of the mammary areola preceding cancer of the mammary gland. St Bartholomew Hospital Reports 1874;10:87-89.

$6 \mathrm{Fu} \mathrm{W,} \mathrm{Lobocki} \mathrm{C,} \mathrm{Silberberg} \mathrm{B,} \mathrm{et} \mathrm{al.} \mathrm{Molecular} \mathrm{markers}$ in Paget's disease of the breast. J Surg Oncol 2001;77:171-178.
7 Shiozaki H, Tahara H, Oka $\mathrm{H}$, et al. Expression of immunoreactive E-cadherin adhesion molecules in human cancers. Am J Pathol 1991;139:17-23.

8 Conman CR. Adhesiveness and stickiness: two independent properties of the cell surface. Cancer Res 1961;21:1436-1438.

9 Takeichi M. Cadherin cell adhesion receptors as a morphogenetic regulator. Science 1991;251:14511455.

10 Behrens J, Mareel MM, Van Roy FM, et al. Dissecting tumour cell invasion: epithelial cells acquire invasion properties after the loss of uvomorulin-mediated cellcell adhesion. J Cell Biol 1989;108:2435-2447.

11 Vleminck K, Vakaet Jr L, Mareel M, et al. Genetic manipulation of E-cadherin expression by epithelial tumour cells reveals invasion suppressor role. Cell 1991;66:107-119.

12 Charpin C, Garcia S, Bonnier P, et al. Reduced E-cadherin immunohistochemical expression in node-negative breast carcinomas. Am J Clin Pathol 1997;109:431-438.

13 Fuller LC, Allen MH, Montesu M, et al. Expression of E-cadherin in human epidermal non-melanoma cutaneous tumours. Br J Dermatol 1996;134:28-32.

14 Bringuier PP, Umbas R, Schaafsma E. Decreased E-cadherin immunoreactivity correlates with poor survival in patients with bladder tumours. Cancer Res 1993;52:5104-5109.

15 Ben Zee'ev A, Geiger B. Differential molecular interactions of beta-catenin and plakoglobin in adhesion, signalling and cancer. Curr Opin Cell Biol 1998;10:629-639.

16 Barker N, Morin PJ, Clevers H. The Yin-Yang of TCF/ beta-catenin signalling. Adv Cancer Res 2000;77: $1-24$.

17 Willert K, Nusse R. Beta-catenin: a key mediator of Wnt signalling. Curr Opin Genet Dev 1998;8:95-102.

18 Ellis PE, Wong Te Fong LF, Rolfe KJ, et al. The role of p53 and Ki67 in Paget's disease of the vulva and breast. Gynecol Oncol 2002;86:150-156.

19 Ellis PE, Wong Te Fong LF, Rolfe KJ, et al. The role of vascular endothelial growth factor-A (VEGF-A) and platelet-derived endothelial cell growth factor/thymidine phosphorylase (PD-ECGF/TP) in Paget's disease of the vulva and breast. Anticancer Res 2002;22:857861.

20 Tada H, Hatoko M, Muramatsu T, et al. Expression of E-cadherin in skin carcinomas. J Dermatol 1996;23: 104-110.

21 Shirahama S, Furukawa F, Wakita H, et al. E- and P-cadherin expression in tumour tissues and soluble E-cadherin levels in sera of patients with skin cancer. J Dermatol Sci 1996;13:30-36.

22 Oka H, Shiozaki H, Kobayashi K, et al. Expression of E-cadherin cell adhesion molecules in human breast cancer tissues and its relationship to metastasis. Cancer Res 1993;53:1696-1701.

23 Miyata M, Shiozaki H, Iihara K, et al. Relationship between E-cadherin expression and lymph node metastasis in human oesophageal cancer. Int J Oncol 1994;4:61-65.

24 Tada H, Hatoko M, Tanaka A, et al. Expression of desmoglein I and plakoglobin in skin carcinomas. qJ Cutan Pathol 2000;27:24-29.

25 Sparks PJ, Korinek V, Barker N, et al. Activation of $\beta$-catenin-Tcf signalling in colon cancer by mutations $\beta$-catenin or APC. Science 1994;275:1787-1790. 
26 Morin P, Sparks A, Korinek V, et al. Activation of $\beta$-catenin-Tcf signalling in colon cancer by mutations in $\beta$-catenin or APC. Science 1997;275:1787-1790.

27 Oka H, Shiozaki H, Kobayashi K, et al. Expression of E-cadherin cell adhesion molecules in human breast cancer tissues and its relationship to metastasis. Cancer Res 1993;53:1696-1701.

28 Lipponen P, Saarelainen E, Ji H, et al. Expression of E-cadherin (E-CD) as related to other prognostic factors and survival in breast cancer. J Pathol 1998;174:101109.

29 Soler AP, Knudsen KA, Salazar H, et al. P-cadherin expression in breast carcinomas indicate poor survival. Cancer 1999;86:1263-1272.

30 Bukholm IK, Nesland JM, Karesen R, et al. E-cadherin and $\alpha$-, $\beta$ - and $\gamma$-catenin protein expression in relation to metastasis in human breast carcinoma. J Pathol 1995;185:262-266.

31 Zschiesche W, Schonborn I, Behrens J, et al. Expression of E-cadherin and catenins in invasive mammary carcinomas. Anticancer Res 1997;17:561-567.

32 Sommers CL, Gelmann EP, Kemler R, et al. Alterations in beta-catenin phosphorylation and plakoglobin expression in human breast cancer cells. Cancer Res 1994;54:3544-3552.

33 Aberle H, Bierkamp C, Torchard D, et al. The human plakoglobin gene localizes on chromosome 17q21 and is subjected to loss of heterozygosity in breast and ovarian cancers. Proc Natl Acad Sci USA 1995;92:6384-6388.

34 Muzio LO, Staibano S, Pannore G, et al. Beta and gamma catenin expression in oral squamous cell carcinoma. Anticancer Res 1999;19:3817-3826. 